Published by Al-Nahrain College of Medicine P-ISSN 1681-6579

E-ISSN 2224-4719

Email: iraqijms@colmed-alnahrain.edu.iq

http://www.colmed-alnahrain.edu.iq

http://www.iraqijms.net

Iraqi JMS 2018; Vol. 16(4)

\title{
Phage Cocktails Against Highly Multi-Drug Resistant Acinetobacter baumanii
}

\author{
Hayder N. Jasim MSc, Ahmad S. Abdul-Ameer ${ }^{1}$ PhD \\ ${ }^{1}$ Dept. of Microbiology, College of Medicine, Al-Nahrain University, Baghdad, Iraq
}

\section{Abstract \\ Background}

Objective

Methods

Results

Conclusion

Keywords

Citation
Phage therapy is a potential alternative treatment for infections caused by many bacterial species such as Acinetobacter baumannii (A. baumannii), a significant nosocomial pathogen, has evolved resistance to almost all conventional antimicrobial drugs in poor hygiene and conflicts areas like Iraq.

Isolate and apply bacteriophages as alternative therapeutic agents against extensively drugresistant (XDR) and pan-drug-resistant $A$. baumannii and evaluation extracted native endolysin activity.

Twenty-three bacterial samples were collected in Al-Imamein Al-kadhimein Medical City hospital. Phages were isolated from different regions in Baghdad city including (soil, sewage, irrigation channels). Native endolysin was extracted from highly lytic phage that produced halo-like appearance around inhibition zone.

Out of 50 isolates, 23 isolates (46\%) of XDR, pan-drug resistant (PDR) A. baumanii have been isolated from patients with various infections. 136 lytic phages specific to $A$. baumanii were isolated. Each bacterial isolate was sensitive to at least one lytic phage. Phage cocktails were formulated and were shown remarkably minimize the bacterial resistance to individual lytic phages. In addition, the endolysin native activity of lytic phages specific to A. baumanii evaluated in this study revealed a potent antibacterial activity $(>1 \mathrm{log})$ reduction of bacterial density in just one hour of endolysin treatment.

Phage therapy assessed in this study was shown ability to efficiently solve the problems of "superbug" bacteria by lysing effectively most XDR, PDR bacteria in vitro. And, phage cocktails were shown to be superior over single-phage preparations in treating $A$. baumanii with much less resistance rate to therapeutic phages. Furthermore, intrinsic activity of native endolysin revealed promising results to tackling superbug pathogens.

Phage, Phage cocktails, Acinetobacter, native endolysin, extensively drug-resistant (XDR), and pandrug resistant (PDR)

Jasim HN, Abdul-Ameer AS. Phage cocktails against highly multi-drug resistant Acinetobacter baumanii. Iraqi JMS. 2018; 16(4): 357-371. doi: 10.22578/IJMS.16.4.2
List of abbreviations: A. baumanii = Acenitobacter baumanii $\mathrm{CLSI}=$ Clinical and Laboratory Standards Institute, MDR = Multiple drug resistant bacteria, $\mathrm{PDR}=\mathrm{Pan}$ drug resistant bacteria $\mathrm{XDR}=$ Extensive drug resistant bacteria

\section{Introduction}

A ntibiotic resistance is an emerging global health disaster, resulting from the constant use (and misuse) of antibiotics in healthcare ${ }^{(1,2)}$. Acinetobacter baumannii (A. baumannii) is a Gram-negative, capsulated, opportunistic pathogen that is effortlessly spread in hospital intensive care units (ICU) (3). Most of $A$. baumannii clinical isolates are multi-drug resistant (MDR), extensively drug-resistant (XDR), and pan-drug resistant (PDR) bacteria, which greatly restricts the available treatment choices ${ }^{(4)}$. To prevent 
returning to the dark "post antibiotics" era, there is an urgent need for new therapeutic agents against the MDR, XDR, PDR pathogens. To fight these bacteria, the scientists suggest a number of new therapeutics alternatives or complements to antibiotics against the "superbug" pathogens, of which A. baumannii. Interestingly, bacteriophage, or phage, therapy has been placed at the top of table presenting a possible alternative mean to tackle refractory bacterial infections ${ }^{(5)}$.

Phage therapy refers to the utilization of phages to treat bacterial diseases ${ }^{(6)}$. Phages are very abundant in nature (7) and every bacterium is likely to have their own specific viruses that could be utilized as antibacterial agents ${ }^{(8-10)}$. The host range of a given phage is often very specific to the sub-species level, which may confer an advantage over antibiotics if infectious bacteria can be targeted without damaging commensal members of the host microbial community.

The formulation of phage cocktail could save lives of uncountable patients suffering from serious and devastating $A$. baumanii infections resistant to the conventional antibiotics. This highlights the importance of using phage cocktails especially in a country like Iraq where A. baumanii flourishes in poor hygiene and areas of conflicts ${ }^{(11)}$.

The current study aims at testing the efficacy of phage therapy, via using a single phage and a phage cocktail, to treat infections with MDR $A$. baumanii bacteria in vitro and to extract and determine intrinsic activity of native endolysin.

\section{Methods}

\section{Specimen collection and identification}

Fifty samples of bacteria were collected in AlImamein Al-kadhimein Medical City Hospital in Alkademiya, Baghdad. Bacterial sampling was carried out during the period from September 2016 to November 2016. A total of twentythree (23) different $A$. baumanii isolates (11 XDR, 12 PDR), belonging to hospitalized patients with various infections including septicemia, skin infection, severe urinary tract infection, pneumonia, and meningitis, were obtained from the Central Laboratory of the hospital. At the same day, samples were transferred to the laboratory of the Medical Microbiology Department in the College of Medicine, Al-Nahrain University to for cultivated bacteria by using nutrient, MacConkey agar and blood agar then incubate at $37{ }^{\circ} \mathrm{C}$ for $18-24 \mathrm{~h}$. Next day, all bacterial isolates were subjected to a full set of diagnosis including Gram staining, culture, and biochemical tests including Oxidase test, Catalase test, Kligler iron agar (KIA), Indole production test, Motility test, Urease production test, Citrate utilization test, Lactose fermentation test, and growth at $44^{\circ} \mathrm{C}$ test ${ }^{(12)}$. Furthermore, the results of the identification of $A$. baumanii were confirmed by API 20 E system.

\section{Antibiotic susceptibility test}

Antibiotic susceptibility test was carried out on A. baumanii isolates using Kirby-Bauer method (13). Seventeen types of antibiotic disks were used as following Imipenem (10 $\mu \mathrm{g})$, Ciprofloxacin $(5 \mu \mathrm{g})$, Colistin $(10 \mu \mathrm{g})$, Tigacyclin (15 $\mu \mathrm{g})$, Gentamicin (10 $\mu \mathrm{g})$, Cefotaxime (30 $\mu \mathrm{g})$, Ceftazidime $(30 \mu \mathrm{g})$, Ceftriaxone $(30 \mu \mathrm{g})$, Trimethoprim/sulphamethaxazole $(10 \mu \mathrm{g})$, Cefepime $(30 \mu \mathrm{g})$, Levofloxacin $(10 \mu \mathrm{g})$, Piperacillin $(100 \mu \mathrm{g})$, Tobramycin $(10 \mu \mathrm{g})$, Amikacin (30 $\mu \mathrm{g})$, Meropenem (10 $\mu \mathrm{g})$, Aztreonam $(30 \mu \mathrm{g})$ and Amoxicillin-clavulanic acid $(20 \mu \mathrm{g})$. A $0.5 \mathrm{McF}$. 0 rland standards of bacteria was used and inoculated and spread by a sterile swab on Muller-Hinton agar Medium. Antibiotic discs were then placed on inoculated agar plates by forceps. The plates were left in incubator upside down at $37{ }^{\circ} \mathrm{C}$ for 18-24 h.

At Subsequent day, plates were carefully examined for any inhibition zones along with measuring their diameter in millimeters $(\mathrm{mm})$ using a metric ruler. Then, classified as sensitive, intermediate, or resistant, according to the standardized table supplied by Clinical and Laboratory Standards Institute (CLSI) guidelines (14). Furthermore, the results of antibiotics susceptibility test were confirmed by VITEK 2 System. 


\section{Bacteriophage sampling, isolation}

Different crude samples for phage isolation were obtained from different regions in Baghdad city including sewage, farm soil, feces of sheep, chicken litter, and swab from surgical lounge in Al-Imamein Al-kadhimein Medical City Hospital during the period from January 2017 to April 2017. Overnight bacterial broth $(100 \mu \mathrm{l})$ was mixed with $2-3 \mathrm{ml}$ of crude samples, which were derived from sewage, cattle feces, chicken litter that might contain Acinetobacter-specific phages. Then, 2-3 ml, equal volume, of nutrient broth and $2 \mathrm{ml}$ of Lambda buffer were added to the mixture as well. Then, the mixture was incubated overnight at $37{ }^{\circ} \mathrm{C}$ with continuous shaking. Next day, supernatant was taken and 1:10 v/v chloroform was added with gentle shaking for 5-7 $\mathrm{min}$ at room temperature to lyse the remaining bacteria. Then, centrifugation at $1000 \mathrm{~g}$ for $3 \mathrm{~min}$ was carried out to produce primary phage suspension. Subsequently, one $\mathrm{ml}$ of overnight bacterial broth was poured onto nutrient agar plate and spread by sterile swab in order to make bacterial lawn. After 10$20 \mathrm{~min}$, the lawn should have been dried. Ten (10) $\mu$ of primary phage suspension were spotted onto the surface of the bacterial lawn and were allowed to dry before incubating at $37^{\circ} \mathrm{C}$ for $18-24 \mathrm{~h}$ in inverted state. On the next day, if zone of lysis was developed at the spot of the primary phage suspension, a lytic and specific phage for the target bacteria was identified and picked up the inhibition zone by sterile loop and put into $1 \mathrm{ml}$ of Lambda buffer in $1.5 \mathrm{ml}$ sterile Eppendorf tubes, then 1:10 v/v chloroform was added to the lysate with gentle shaking for 5-7 min at room temperature, then, centrifuged at $1000 \mathrm{~g}$ for $3 \mathrm{~min}$ and bacterial cell debris were pelleted, and the supernatant containing phages was transferred to $1.5 \mathrm{ml}$ sterile Eppendorf tubes and stored at $4{ }^{\circ} \mathrm{C}$ for one month. The supernatant was called transient phage stock suspension ${ }^{(15)}$.

\section{Optimization and characterization of isolated phages}

Plaque characteristics were determined using top layer plaque assay and according to the following parameters: a) Diameter $(\mathrm{mm})$ of the plaque. b) Shape of the plaque. c) Depth of the plaque. d) Margin cut. e) Clarity or turbidity of the plaque. Accordingly, the clearest and largest plaques were selected; moreover, small or turbid plaques were subjected to optimization by conducting serial passage in top layer plaque assays; at each run, the best of the best plaques, in terms of the abovementioned parameters, were selected in order to acquire better virulence characteristics of the isolated lytic phages. It is noteworthy to mention that not all turbid and small plaques were optimized. This depends on the potential of the phage to enhance its virulence characteristics ${ }^{(15)}$. In this approach, burst size, burst time, and infection percentage are determined according to (15). One hundred (100) $\mu \mathrm{l}$ of $106 \mathrm{PFU} / \mathrm{ml}$ of phage were added to $100 \mu \mathrm{l}$ of $104 \mathrm{CFU} / \mathrm{ml}$ of target bacterial broth culture at $\mathrm{MOI}$ equal to 100 . This mixture was dispensed into a sterile $1.5 \mathrm{ml}$ Eppendorf tube and then incubated at $37{ }^{\circ} \mathrm{C}$ for 5-10 min to allow the phage to enter into bacterial host (phage contact time). Then, the mixture of phage-bacteria was centrifuged at room temperature at $1000 \mathrm{~g}$ for $3 \mathrm{~min}$. Subsequently, the pellet was re-suspended in one $\mathrm{ml}$ of nutrient broth (this step was repeated 3 times). The aim of this step is to remove all of the extracellular phages and to neglect the supernatant and keep only the bacterial cells infected with specific phages. Afterwards, the re-suspended tube was ten-fold serially diluted (10-1-10--2) by adding $100 \mu \mathrm{l}$ of the suspension to $900 \mu \mathrm{l}$ of nutrient broth. Ten $\mu \mathrm{l}$ from each dilution were spotted on target bacterial lawn at timely intervals; 20, 25, 30, 35, 40, and 45 $\mathrm{min}$, then, let the plate get wet and incubated overnight at $37{ }^{\circ} \mathrm{C}$. Next day, the plaques were counted to calculate the infection percentage, burst time, and burst size ${ }^{(15)}$ as follows:

Infective percentage (IP \%): refer to the percentage of specific lytic phages that invade the target bacteria. This percentage was calculated by dividing the number of plaques during the pre-burst time over the number of bacteria used in the assay. Burst time (BT): refer to the time required by the infecting 
phages to burst and exist from bacterial cells. So, BT is the period before a sharp rise was detected in the number of the progeny phage particles for the certain dilution. Burst size (BS): refer to the number of the new progenies of phage per one cell of target bacteria. BS was calculated by dividing the number of plaques post- burst time over the number of plaques pre-burst time ${ }^{(15)}$.

Testing of bacterial resistance rate of $A$. baumanii to infecting bacteriophages

The resistance rate of bacteria to infecting phages was measured. A piece from the same bacterial lawn of the target bacteria that is equal in diameter to phage lysis spot was cut by a sterile loop and put in $1.5 \mathrm{ml}$ sterile Eppendorf tube containing one $\mathrm{ml}$ of normal saline. This approach is to obtain the same number of bacteria that was present in the phage spot lysis zone. Then, the tube was subjected to periodic shaking for $5 \mathrm{~min}$. Then, tubes were centrifuged at $1000 \mathrm{~g}$ for $3 \mathrm{~min}$ at room temperature. Afterwards, the supernatant was removed and the precipitate was re-suspended in one $\mathrm{ml}$ of normal saline (15).

Ten-fold serial dilutions of the resulting bacterial suspension (10-1-10-5) were made. Then, $10 \mu \mathrm{l}$ drop of the bacterial suspension was spotted on a nutrient agar plate inclined 45 degrees in one direction in order to spread the drop to one direction forming lines at which counting of bacterial colonies becomes much easier. The plates were incubated at 37 ${ }^{\circ} \mathrm{C}$ for $24 \mathrm{~h}$. The bacterial resistance rate was calculated as the following ${ }^{(15)}$ :

Resistance rate $=$ Number of resistant colonies per phage lysis spot / number of bacterial colonies formed from the same size cut of bacterial lawn.

Determination of the coverage rate of bacteriophage cocktails to $A$. baumanii

In this approach, after mixed numerous phages in one suspension, randomly sampled $10 \mathrm{~A}$. baumanii isolates were collected from patients in Al-Imamein Al-kadhimein Medical City Hospital. Ten (10) $\mu \mathrm{l}$ of bacteriophage cocktails suspension were spotted on to the surface of the overnight bacterial lawn and were allowed to dry before incubating at $37^{\circ} \mathrm{C}$ for $24 \mathrm{~h}$. On the next day, if a zone of lysis was developed at the spot where the phages suspension was applied, a susceptible bacterial isolate to phage cocktail was found. Then, the coverage rate of the formed bacteriophage cocktails was measured using this formula:

Coverage rate $=$ (number of bacteria lysed by cocktails / total number of bacteria) $\times 100 \%$.

The assessment of the activity of phage Endolysin on A.r baumanii bacteria

\section{Extraction of Endolysin}

About $100 \mathrm{ml}$ of broth of $A$. baumanii bacteria were incubated for $18-24 \mathrm{~h}$ at $37^{\circ} \mathrm{C}$. Next day, $250 \mathrm{ml}$ of broth medium were added to the bacterial broth and incubated for another 3 hours at titer $1 \times 10^{9} \mathrm{CFU} / \mathrm{ml}$. Up to $10 \mathrm{ml}$ of phage at titer $1 \times 10^{11} \mathrm{PFU} / \mathrm{ml}$ (1:100 MOI) were mixed with bacteria for 20 minutes and then put them directly in ice. Centrifugation at 10,000 $\mathrm{g}$ for 20 minutes and take the sediment. The sediment was suspended in $10 \mathrm{ml}$ of 0.05 $\mathrm{M}$ phosphate buffer $+5 \mathrm{mg}$ deoxyribonuclease and incubated for $60 \mathrm{~min}$ at $37^{\circ} \mathrm{C}$. And $0.005 \mathrm{M}$ EDTA was added and centrifugation at $10,000 \mathrm{~g}$ for $1 \mathrm{~h}$ and then the supernatant was taken. Disodium tetrathionate $(0.3 \mathrm{M})$ was added and mixed for one hour at 4 으. Ammonium sulfate was added to $85 \%$ saturation and incubated for 18-24 $\mathrm{h}$ at $4{ }^{\circ} \mathrm{C}$. Next day, centrifugation at $10,000 \mathrm{~g}$ for $1 \mathrm{~h}$ and resuspended in $5 \mathrm{ml}$ of 0.05 $\mathrm{M}$ phosphate buffer saline (PH 7.5). Dialysis against $200 \mathrm{ml}$ of the buffer at $4{ }^{\circ} \mathrm{C}$ was conducted. The resultant solution was added to column chromatography sephadex G.100 in $0.1 \mathrm{M}$ phosphate buffer saline PH 7.5, in $18 \times 0.5$ $\mathrm{cm}$ column. Each one $\mathrm{ml}$ of the resultant filtrate was collected in Eppendorf tubes. From each Eppendorf tube, $10 \mu \mathrm{l}$ of the filtrate were dropped by automatic pipette onto $A$. baumanii bacterial lawns of the specific bacteria to see which Eppendorf tube contains the lytic and native activity of endolysin. 
Measurement of the native activity of Endolysin on A. baumanii bacteria

Upon using sephadex G100 chromatography, the used phage (AB3P5) gave 10 Eppendorf tubes of one $\mathrm{ml}$ eluted fluid; in case endolysin was extracted, at least one of these tubes must show a lytic activity against the corresponding $A$. baumanii isolate. The endolysin activity was first checked by lysis on bacterial lawn and second by decreasing the optical density of the bacterial broth when measured by a spectrophotometer. A. baumanii broth was composed of bacterial cells growing at mid-log phase $(\mathrm{OD600}=0.6)$ and were centrifuged ( $4000 \mathrm{~g}, 30 \mathrm{~min}, 4^{\circ} \mathrm{C}$ ) and then re-suspended in a phosphate-buffered saline (PBS) at PH (7.5). After assigning the tube that showed lysis in the bacterial lawn assay, $30 \mu \mathrm{l}$ of this supposed-to-be endolysin-containing elute were added to $270 \mu \mathrm{l}$ of the prepared bacterial broth at room temperature. Then, the optical density was measured spectrophotometrically every ten minutes for $1 \mathrm{~h}$ at $600 \mathrm{~nm}^{(16)}$.

\section{Results}

\section{Characteristics of the isolates of $\boldsymbol{A}$. baumanii}

The characteristic features of the bacterial isolates used were the site of infection, patient's sex, patient's age, and the disease or lesion from which bacterial isolates were taken. As shown in table 1, the patients were infected with virulent bacteria causing serious and life-threatening diseases including urinary tract infection, septicemia, wound infection, pneumonia, and meningitis. A total of $23 \mathrm{~A}$. baumanii isolates were collected. The specimens from which $A$. baumanii were isolated are as follows: blood $7 / 23$ (30.4\%), urine $2 / 23(9 \%)$, wound swab $7 / 23(30.4 \%)$, diabetic foot $3 / 23(13 \%)$, sputum $2 / 23(9 \%)$, and C.S.F $2 / 23$ (9\%). The diseases from which $A$. baumanii bacteria were isolated wound infection 10/23 (43.4\%), urinary tract infection 2/23 (9\%), septicemia 9/23 (39.1\%), pneumonia $2 / 23(9 \%)$, and meningitis $2 / 23$ (9\%) (Tables $1 \& 2$ ). Hence, the most prevalent disease related to $A$. baumanii was wound infection followed by septicemia. The age of patients ranged from 1 day to 70 years and male to female ratio was 2.3:1.

All bacterial isolates appeared as Gramnegative coccobacilli and occasionally arranged in diplococci. All of the isolates were tested for biochemical tests and $A$. baumanii showed negative results for oxidase, motility, indole production and urease production tests, and positive results to catalase and citrate utilization tests; Kligler iron agar test developed an alkaline slant, no change at bottom, H2S negative without gas production. Also, when $A$. baumanii isolates were cultured on MacConkey agar, they appeared as small, pale and lactose non-fermenter colonies, while on blood agar they appeared as opaque, creamy and non-hemolytic colonies. Growth at 44 으 was positive for all $A$. baumanii isolates which showed the ability to grow at this temperature degree. This test was used to distinguish $A$. baumanii (which was able to grow at this temperature) from other Acinetobacter species which are unable to grow at this temperature degree.

\section{Antibiotic sensitivity test}

The results showed that different $A$. baumanii isolates had different antibiotic sensitivity profiles; of 23 isolates included in the current study, 11 were XDR and 12 were PDR. As shown in Figure 1.

\section{The characteristic features of the isolated and optimized phages}

The characteristics of plaque assay of the isolated phages showed that plaques clarity (clear, semi-clear, turbid, semi-turbid), plaques size was varied and ranged between $0.5 \mathrm{~mm}$ to $6.5 \mathrm{~mm}$, margin cut (regular and irregular), and plaques shape (oval and circular).

One hundred and thirty-six (136) phages specific for 23 A. baumanii bacteria were isolated. The specimens were obtained mainly from sewage and also from irrigation channels, then from waste water, soil, feces of sheep, chicken litter and swab from lounge. However, most of the isolated phages were highly lytic 
and produced obvious inhibition zone on target $A$. baumanii bacteria where plaque size was higher than $3 \mathrm{~mm}$ with full clarity of plaques; therefore, further optimization was not needed save for 25 phages which required further optimization in order to increase their lytic characteristics, (Table 1). The titer of the specific lytic phages isolated and optimized to the bacterial isolates were amplified and measured by using top layer plaque assay. Most phages reached high titers ranging between 108-1011 PFU/ml using top layer plaque assay. The optimized specific and lytic phages were shown to be able to completely lyse the bacterial host in whatever manner of application of phages as demonstrated in figures 2 and 3.

The characteristics of the isolated and optimized phages in terms of biokinetic assay In the current study, 10 bacteriophages to different bacterial isolates were randomly selected to give representative values of biokinetic characteristics. The results in this study showed that the average burst time (BT) was $73.5 \mathrm{~min}$ ranging between 30 to $45 \mathrm{~min}$. The maximum burst size (BS) of the randomly selected phages to $A$. baumanii was 245 progenies, while the minimum BS was 130 progenies and the average BS was 187.5 progeny. The average infective percentage (IP $\%$ ) was $85.45 \%$ ranging between $74.4 \%$ and $94.5 \%$, as shown in table (3).

\section{Formation of phage cocktail to Acinetobacter baumanii}

A phage cocktail was formed by mixing 64 phages specific for $23 \mathrm{~A}$. baumanii isolates (AB1-AB23). One hundred, $100 \mu \mathrm{l}$ of $10^{6}$ $\mathrm{PFU} / \mathrm{ml}$ of each phage were collected in one tube to form a bacteriophage stock containing a wide range of isolated phages. All bacterial isolate, except $A B 2$ and $A B 8$, were targeted by more than one phage; the most targeted isolate was AB3 where 6 different phages shared the same specificity towards this isolate.

\section{Bacterial resistance to a single phage versus phage cocktail}

Up to $18 / 23$ (78.3\%) of $A$. baumanii bacteria were completely sensitive to the applied lytic phages with zero resistant bacterial colonies. So, only 5 out of 23 isolates (21.7\%) of $A$. baumanii were shown to develop some level of resistant colonies in the inhibition zone at the spot of lytic phage application. On other hand, the formed phage cocktail was shown to remarkably minimize the number of the resistant bacterial colonies appeared to individual phages. The results revealed that once $A$. baumanii isolate develops resistance to one member of phage cocktails, the bacterial isolate was still sensitive and lysed by other phage members in the cocktails as shown in figure 4.

The coverage rate of the formed phage cocktail to $A$. baumanii bacteria

Ten (10) $A$. baumanii isolates were collected from patients resided in Al-Imamein Alkadhimein Medical City Hospital. The collected specimens were not biased towards particular disease, site of infection, or patients' age or sex. Full sets of identification were performed, then the results of identification of $A$. baumanii confirmed by API 20E system.

The formed phage cocktail was able to form a clear inhibition zone on the most tested bacterial lawns. The coverage rate of the formed phage cocktail was calculated. The phage cocktail was shown to be able to lyse $7 / 10(70 \%)$ of $A$. baumanii bacteria and thus the coverage rate was $70 \%$. 
Table 1. The characteristic features of $A$. baumanii bacteria to which the lytic and specific phages were isolated

\begin{tabular}{ccccc}
\hline Bacterial isolate & Specimen & Age of patient & $\begin{array}{c}\text { Sex of } \\
\text { patient }\end{array}$ & Disease \\
\hline AB1 & Wound swab & 30 years & Male & Wound infection \\
AB2 & Urine & 40 years & Female & Urinary tract infection \\
AB3 & Blood & 7 years & Female & Septicemia \\
AB4 & Throat swab & 4 days & Female & Pneumonia \\
AB5 & Wound swab & 6 years & Male & Wound infection \\
AB6 & Wound swab & 37 years & Male & Wound infection \\
AB7 & Blood & 35 years & Male & Septicemia \\
AB8 & Blood & 1 day & Male & Septicemia \\
AB9 & Blood & 5 days & Male & Septicemia \\
AB10 & Blood & 3 days & Male & Septicemia \\
AB11 & Wound swab & 2 months & Male & Wound infection \\
AB12 & Wound swab & 33 years & Male & Wound infection \\
AB13 & Sputum & 38 years & Male & Pneumonia \\
AB14 & Diabetic foot & 40 years & Female & Wound infection \\
AB15 & Wound swab & 70 years & Male & Wound infection \\
AB16 & CSF & 43 years & Female & Meningitis \\
AB17 & Blood & 2 years & Female & Septicemia \\
AB18 & Wound swab & 12 years & Male & Wound infection \\
AB19 & Diabetic foot & 41 years & Male & Wound infection \\
AB20 & Blood & 55 years & Male & Septicemia \\
AB21 & Diabetic foot & 2 years & Female & Wound infection \\
AB22 & Urine & 67 years & Male & Urinary tract infection \\
AB23 & CSF & 14 days & Male & Meningitis \\
\hline
\end{tabular}

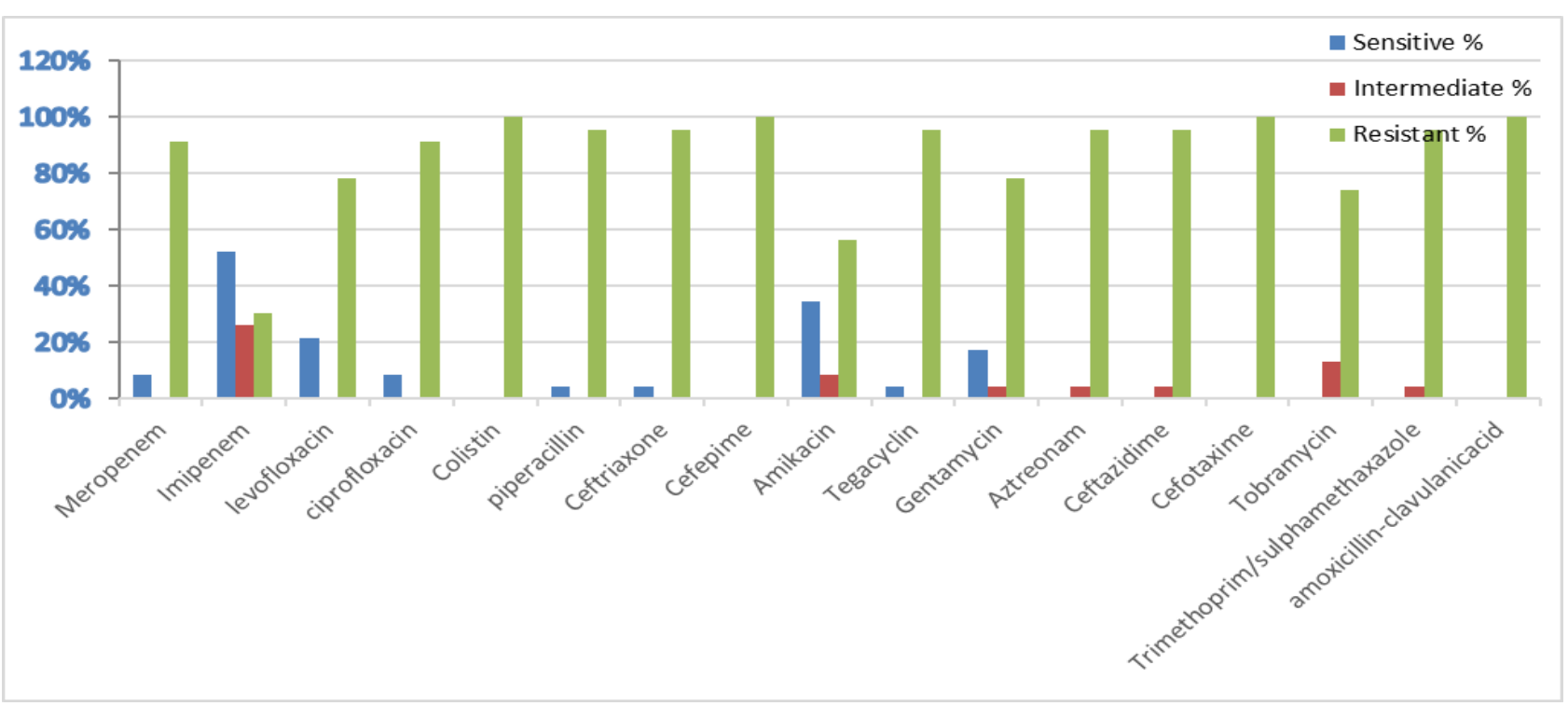

Figure 1. The rate of antibiotic sensitivity/ resistance of 23 A. baumanii isolates to a panel of 17 antibiotic disks commonly used in Iraq 


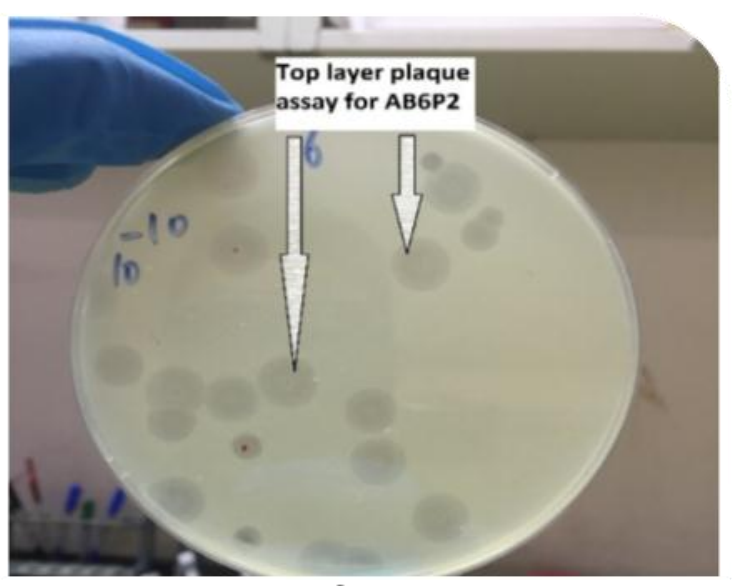

A

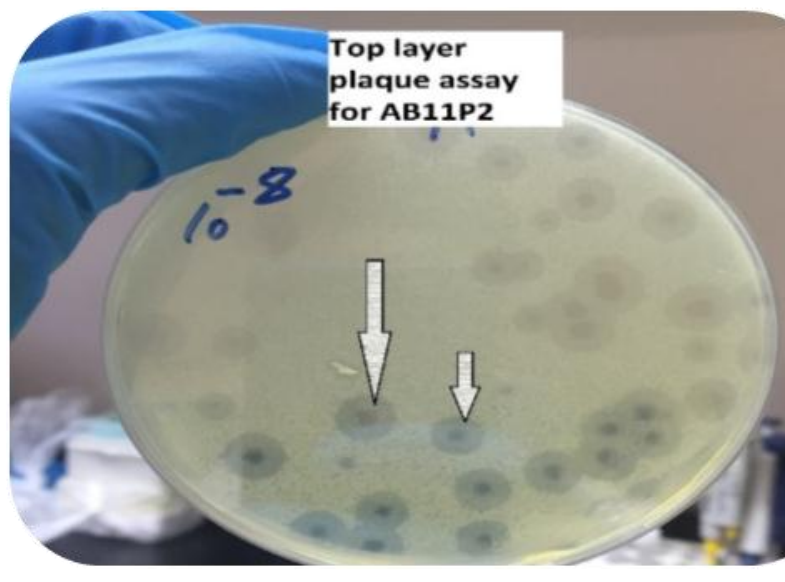

B

Figure 2. A) plaques produced by of $A B 6 P 2$ via top-layer plaque assay $B$ ) plaques produced by $A B 11 P 2$ via top-layer plaque assay

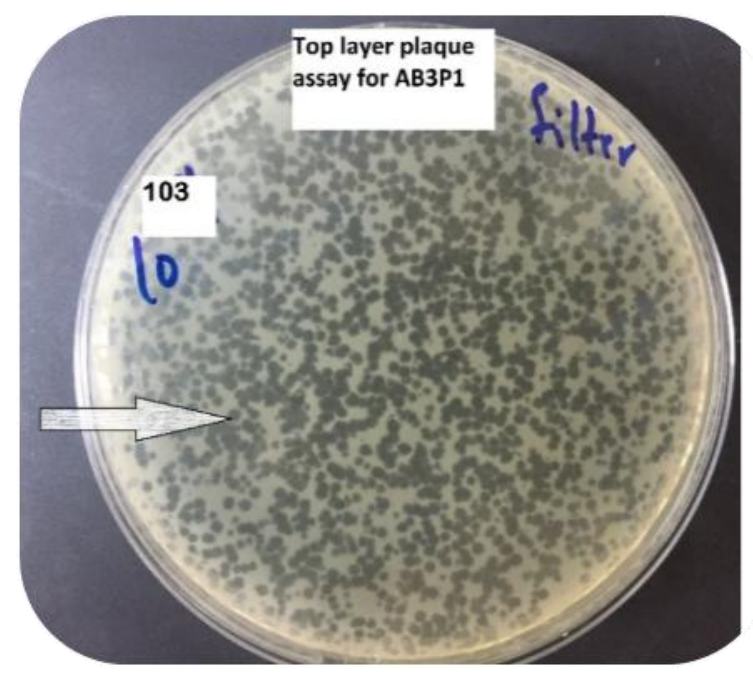

A

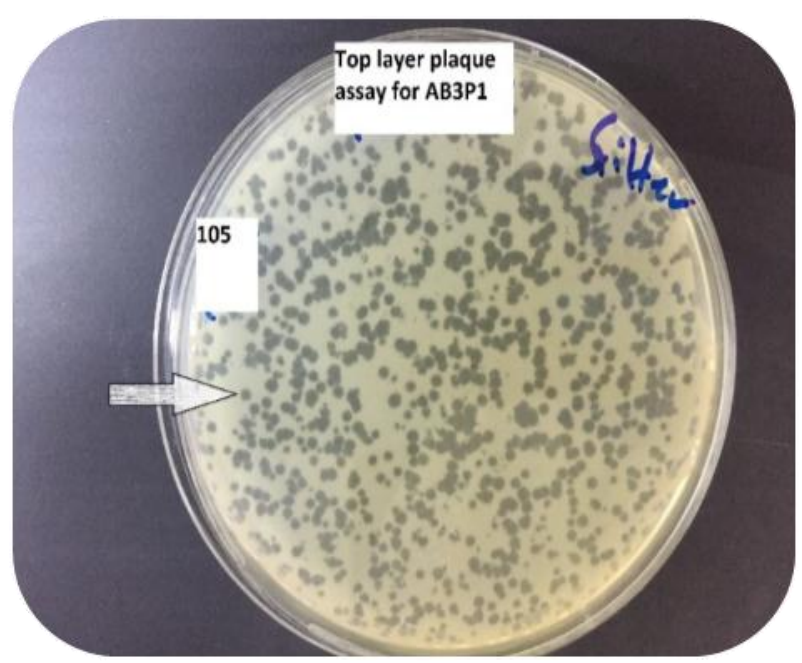

B

Figure 3. Top layer plaque assay for AB3P1 with different concentrations A) AB3P1 with 103 PFU/ml B) AB3P1 with 105 PFU/ml 
Table 2. Morphological features of the isolated phages to A. baumanii bacteria before and after optimization via top layer plaque assay

\begin{tabular}{|c|c|c|c|c|c|c|c|c|}
\hline \multirow{2}{*}{$\begin{array}{c}\begin{array}{c}\text { Phage } \\
\text { symbol }\end{array} \\
\text { Befor }\end{array}$} & \multicolumn{2}{|c|}{$\begin{array}{l}\text { Plaque size } \\
\text { (mm) }\end{array}$} & \multicolumn{2}{|c|}{ Plaque clarity } & \multicolumn{2}{|c|}{ Plaque shape } & \multicolumn{2}{|c|}{ Margin cut } \\
\hline & & After & Before & After & Before & After & Before & After \\
\hline AB1P1 & 0.5 & 1.5 & Turbid & Semi-clear & Round & Round & Un-obvious & Regular \\
\hline AB1P2 & 0.3 & 1 & $\begin{array}{l}\text { Semi- } \\
\text { turbid }\end{array}$ & Clear & Round & Round & Irregular & Irregular \\
\hline AB2P1 & 2 & 2.5 & Semi-clear & Semi-clear & Round & Round & Regular & Regular \\
\hline AB3P1 & 0.8 & 1.5 & $\begin{array}{l}\text { Semi- } \\
\text { turbid }\end{array}$ & Semi-clear & Oval & Oval & Irregular & Irregular \\
\hline AB3P2 & 0.5 & 0.5 & Semi-clear & Clear & Oval & Oval & Regular & Regular \\
\hline AB3P3 & 2.5 & 4 & Semi-Clear & Clear & Round & Round & Irregular & Irregular \\
\hline AB3P4 & 3.5 & 3.5 & Semi-Clear & Clear & Oval & Oval & Irregular & Irregular \\
\hline AB4P1 & 3.5 & 7 & Clear & Clear & Round & Round & Irregular & Irregular \\
\hline AB5P1 & 1 & 1.5 & Turbid & Clear & Oval & Oval & Un-obvious & Irregular \\
\hline AB6P1 & 2 & 2 & $\begin{array}{l}\text { Semi- } \\
\text { turbid }\end{array}$ & Semi-clear & $\begin{array}{l}\text { Semi- } \\
\text { round }\end{array}$ & Round & Irregular & Regular \\
\hline AB6P2 & 2 & 3.5 & Semi-clear & Semi-clear & Oval & Oval & Irregular & Irregular \\
\hline AB9P1 & 0.5 & 0.5 & Semi-Clear & Clear & Round & Round & Regular & Regular \\
\hline AB10P1 & 1.2 & 2.5 & Clear & Clear & Round & Round & Regular & Regular \\
\hline AB10P2 & 1.9 & 5.5 & $\begin{array}{l}\text { Semi- } \\
\text { turbid }\end{array}$ & Clear & Round & Round & Regular & Regular \\
\hline AB12P1 & 1 & 1 & $\begin{array}{l}\text { Semi- } \\
\text { turbid }\end{array}$ & $\begin{array}{l}\text { Semi- } \\
\text { turbid }\end{array}$ & Oval & Oval & Irregular & Irregular \\
\hline AB15P1 & 3.5 & 5.5 & Turbid & Clear & Round & Round & Un-obvious & Regular \\
\hline$A B 15 P 2$ & 0.8 & 1 & $\begin{array}{l}\text { Semi- } \\
\text { turbid }\end{array}$ & Clear & Round & Round & Regular & Regular \\
\hline AB17P1 & 1.7 & 3.5 & Semi-Clear & Clear & Oval & Oval & Irregular & Irregular \\
\hline AB19P1 & 0.5 & 3 & $\begin{array}{l}\text { Semi- } \\
\text { turbid }\end{array}$ & $\begin{array}{l}\text { Semi- } \\
\text { turbid }\end{array}$ & Round & Round & Un-obvious & Irregular \\
\hline AB19P2 & 0.8 & 1.5 & Turbid & Clear & Round & Round & Un-obvious & Regular \\
\hline AB20P1 & 0.5 & 2 & Semi-Clear & Clear & Oval & Oval & Regular & Regular \\
\hline AB21P1 & 1.5 & 6.5 & Turbid & Semi-clear & Oval & Oval & Regular & Regular \\
\hline AB21P2 & 1 & 2 & $\begin{array}{l}\text { Semi- } \\
\text { turbid }\end{array}$ & Semi-clear & Round & Round & Irregular & Irregular \\
\hline AB22P1 & 0.5 & 1.5 & Turbid & Turbid & Oval & Oval & Un-obvious & Regular \\
\hline AB22P2 & 2.3 & 4.5 & $\begin{array}{l}\text { Semi- } \\
\text { turbid }\end{array}$ & $\begin{array}{l}\text { Semi- } \\
\text { turbid }\end{array}$ & Oval & Oval & Irregular & Irregular \\
\hline
\end{tabular}


Table 3. Shown the biokinetics: Infective percentage (IP \%), Burst time (BT) in minutes, and Burst size (BS) in number of progenies of the randomly selected bacteriophages to $A$. baumanii bacteria

\begin{tabular}{lccc}
\hline & IP \% & BT & BS \\
\hline AB1P2 & 91.3 & 40 & 170 \\
AB3P4 & 94.5 & 45 & 245 \\
AB5P1 & 76.4 & 35 & 220 \\
AB7P3 & 85.2 & 30 & 160 \\
AB9P1 & 88 & 45 & 210 \\
AB10P2 & 86.6 & 45 & 145 \\
AB14P1 & 77.5 & 40 & 190 \\
AB15P3 & 82 & 30 & 200 \\
AB17P2 & 80 & 40 & 130 \\
AB20P1 & 79 & 35 & 185 \\
\hline
\end{tabular}
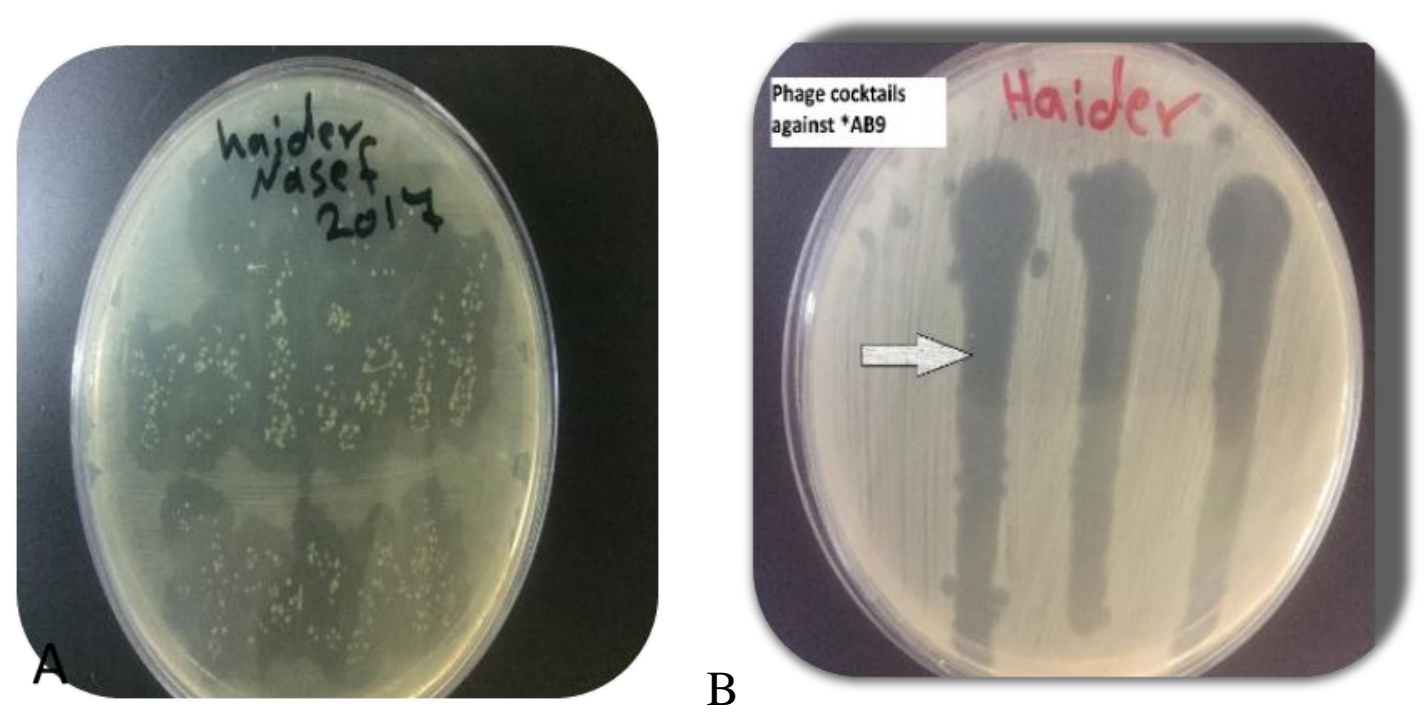

Figure 4. (A) resistant $A$. baumanii bacteria (AB3) to a single specific phage (AB3P1) (B) the phage cocktail completely lysed $A$. baumanii (AB3) bacteria without development of any resistant colonies

Determination of the native activity of phage Endolysin on A. baumanii bacteria

During the isolation and optimization of different phages against $A$. baumanii isolates; some phages were found to produce a halo-like appearance around the inhibition zone produced by some lytic phages as shown in figure 6. This halo-like appearance suggested a native endolysin production from phage. The findings of this study revealed that a specific phage endolysin to $A$. baumanii was extracted successfully by using sephadex G100 column chromatography. The Eppendorf tube number two showed positive results for phage 
endolysin. The optical density of $A$. baumanii broth was measured initially at zero time, just before the addition of the corresponding endolysin, then it was measured every ten minutes for complete one hour and it showed obvious decline in optical density of bacterial broth with time. According to t-distribution test, there is a significant difference between the test groups, bacteria treated with endolysin and control group, bacteria alone with PBS, $(\mathrm{P}=$ 0.00134). Moreover, the overall enzymatic activity of extracted native endolysin was quantified by turbidometric reduction analysis, $270 \mu$ of exponentially growing $A$. baumanii
(AB3) cultures $(1.4 \times 108 \mathrm{CFU} / \mathrm{ml})$ were challenged to $30 \mu \mathrm{l}$ of extracted native endolysin at room temperature. A. baumanii optical density and viability counts were reduced from 0.585 to 0.031 after one hour of treatment, compared with the untreated control group that continued to grow (from 577 to 624 after one hour). It was shown to be $-0.0092 \Delta \mathrm{OD} / \mathrm{min}$. By using standard curve measurements to interpolate $O D$ values to bacterial count, it was shown that the endolysin native activity surpassed $1.4 \mathrm{log}$ reduction threshold after one hour of treatment as shown in figure 5 .

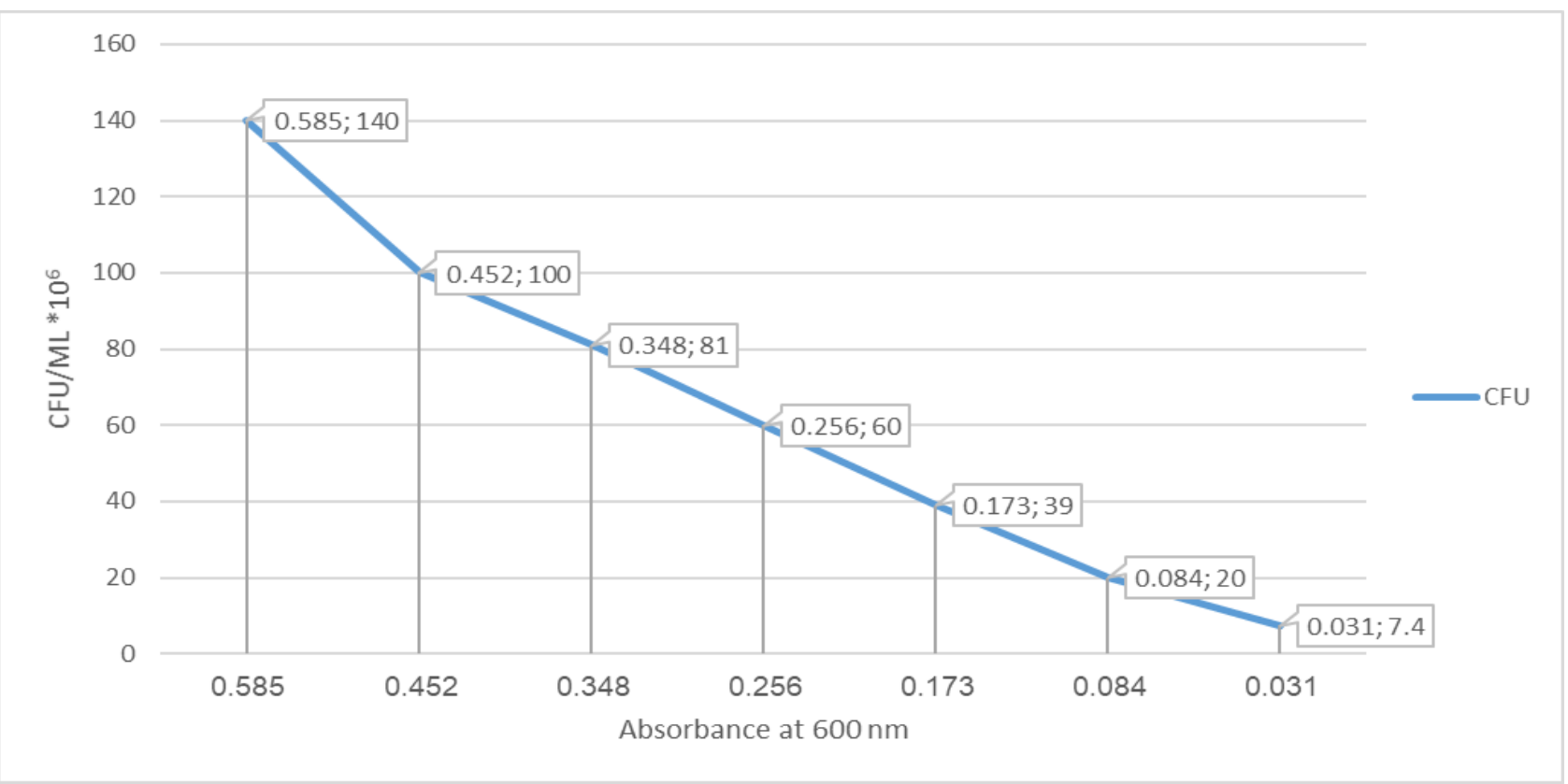

Figure 5. Interpolation of bacterial count in CFU/ml with the optical density $(600 \mathrm{~nm})$ of $A$. baumanii broth treated with $\mathrm{AB} 3$ phage endolysin

\section{Discussion}

The results in the current study revealed different antibiotic resistant profiles by different $A$. baumanii isolates. All of the isolates of $A$. baumanii were shown to be fully resistant to several antibiotics tested in the current study and as follows: Cefepime, Cefotaxime, Colistin, and Amoxicillin-clavulanic acid. However, the resistance rate to other antibiotics was less than $100 \%$ and ranged from
$95.65 \%$ to $30.43 \%$. The MDR status reported in current study agrees with the findings of other recent studies carried in Iraq ${ }^{(17-19)}$ but this study disagrees with a study carried out in USA which reported that approximately $50 \%$ of patients are with colistin-resistant $A$. baumannii ${ }^{(20)}$. The variation in the results may be due to sample size, sampling procedure, differences in the time of the studies, or differences in the geographic areas. This study 
agrees with study in Iraq which found that, $A$. baumanni clinical isolates developed $97.3 \%$ of resistance to Aztreonam and Ceftriaxone, $89.5 \%$ to Ceftazidime, and $58.2 \%$ to Imipenem (21). Moreover, this study agrees with another local study conducted in Iraq which found that, a high level of $A$. baumanii resistance, $88.2 \%$ to Meropenem and a lower resistance rate $52.9 \%$ to Imipenem while complete resistance was reported, $100 \%$, to Cefepime, Azteronam, and Ceftriaxone (22). The complete resistance of $A$. baumanii isolates collected in this study to colistin might be attributed to the major mechanism of colistin resistance in $A$. baumannii, namely modification of lipopolysaccharide (LPS) outer membrane via adding phosphor ethanol amine to the hepta acylated lipid A structure (23,24).

The presence of $\beta$-lactamases, which are the backbone of the most principal mechanism of $\beta$-lactam resistance. These enzymes, at least in part, hydrolyze carbapenems along with other $\beta$-lactams (25). Recently a new extended spectrum AmpC enzyme was identified in $A$. baumannii bacteria; this enzyme has been shown to be able to hydrolyze Ceftazidime, Cefepime and Aztroenam ${ }^{(26)}$.

In this regard, bacteriophage or phage therapy could offer one of the best applicable solutions to overwhelm the problem of antibiotics resistance of bacteria in Iraq and in the world (27). One of the striking merits of using bacteriophages over antibiotics in a country like Iraq is the fact that phages are selfamplifying in the site of infection so phages can be given to patients in a single dose, therefore, unnecessary to repeat doses of phages; hence, incompliance of patients will not affect the success of the course of therapy. In this study, the lytic and specific phages to $A$. baumanii were isolated from various environmental sources; the main source was sewage; this finding is in line with other studies $(28,29)$. Another main source of phages in this study was waste water (30). The current study revealed that sewage was the best source to isolate highly lytic and specific phages to $A$. baumanii (31). Moreover, phages from sewage showed good clarity and size of plaques; this might be credited to the fact that phages in sewage tolerate drastic environment which favors the induction of temperate phages, residing in high number in Acenitobacter bacteria, to lytic ones.

The current study showed successful in vitro use of both single phage and phage cocktail to lyse $A$. baumanii XDR or PDR isolates. Nevertheless, this study revealed a superiority of the phage cocktail over the single phage in lysing $A$. baumanii bacteria without development of resistant colonies to phage therapy. Consequently, such phage cocktails are powerfully supposed to prevent the emergence of phage-resistant mutants (16,32). The results of the current study highlighted the fact that using phage cocktails provides several advantages. Firstly, phage cocktails broaden the strain-specific range of infective phages. This permits effective therapy of a broader spectrum of bacteria within the same $A$. baumanii species $(33,34)$. Secondly, phage cocktails solve the serious obstacle of the development of $A$. baumanii resistance to attacking phages. It was stated that using phage cocktails is the finest choice for effective phage therapy without suspicions of rapid emergence of bacterial resistance (33). The phage cocktail used in this study ensured two important goals, covering as much as possible different strains of $A$. baumanii, and the second goal is that each bacterial isolate was recognized by multiple different phages, a necessary step to combat bacterial resistance to phage therapy. Each $A$. baumanii isolate might have more than one receptor and each receptor is recognized by a different phage to attach and invade (35). This explains why each bacterial isolate was invaded by more than one different phage. Therefore, when a bacterial isolate develops resistance to one phage in the phage cocktail, it is still sensitive to other phages in the same phage cocktail. From the findings of the top layer plaque assay of this study, each member of the phage cocktail was different from each other, and from the findings of the bacterial resistance rate to the single phage versus the phage cocktail, the phages used in this study seem to target different receptors on the cell wall of $A$. baumanii bacteria. This provides evidence on 
the preferred use of phage cocktails in the phage therapy of superbugs like $A$. baumanii XDR and PDR bacteria tested in this study.

The coverage rate of the formed bacteriophage cocktail in this study was shown to be very high, up to $70 \%$. Such high coverage paves the road to successful and ready-to-use therapy of serious and life-threatening infections of $A$. baumanii. Nevertheless, in this study, it was proven that in few months and by a single researcher, a phage cocktail of 64 anti-A. baumanii specific and lytic phages was formed. The formed phage cocktail could save lives of uncountable patients suffering from serious and devastating $A$. baumanii infections resistant to the conventional antibiotics. This highlights the importance of using phage cocktails especially in a country like Iraq where A. baumanii flourishes in poor hygiene and areas of conflicts $(36,37)$.

The results of the native endolysin activity in the current study are in a harmony with few studies examined the native activity of endolysin produced from bacteriophages that infect gram-negative bacteria such as $A$. baumanii, $P$. aeruginosa and $E$. coli ${ }^{(38-42)}$. The current study highlights the intrinsic antimicrobial activity of native endolysin produced from phages against G-ve bacterial pathogens. Native endolysin activity is a good candidate for the therapeutic/disinfectant endeavor to control nosocomial infections caused by multiple drug-resistant bacteria, particularly MDR A. baumanii bacteria (38). The intrinsic antibacterial activity of endolysin against G-ve needs the ability of endolysin to get through the outer membrane pf these bacteria. This might explain why endolysins from phages infecting Gram-negative hosts are mostly small single-domain globular proteins (molecular mass between 15 and $20 \mathrm{kDa}$ ), and usually without a specific CBD module (39). These lysins likely better fulfill the catalytic role of classical enzymes (aiding multiple catalytic reactions during cell lysis), as opposed to their Gram-positive counterparts, which are proposed to bind to one site and have a very low off-rate ${ }^{(43,44)}$.

In Acinetobacter, it seems rather unusual that the lysogens would evolve a large diverse group of lysins for the sole purpose of releasing their phage progeny. Researchers guess that these lysins might in some manner be harnessed by the Acenitobacter bacteria to control their environment and fight back competing bacteria of other species ${ }^{(45)}$. Being a soil organism, $A$. baumannii shares a highly competitive niche with further bacteria, including Pseudomonas and Bacillus which have an advantage over $A$. baumannii with their capability of producing several bacteriocin molecules used to kill bacteria in proximity $(46,47)$.

Taken together, the findings of this study indicate that $A$. baumanii bacteria in Iraq are mostly XDR and PDR bacteria; such abnormally high rate of multiple drug resistance necessities novel methods to tackle this impeding health risk on community. Therefore, the phage therapy assessed in this study was shown to be able to efficiently solve the problems of superbug resistant bacteria by lysing effectively most XDR and PDR bacteria in vitro. And, phage cocktails were shown to be superior over single-phage preparations in treating $A$. baumanii with much less rate of resistance to therapeutic phages. In addition, the endolysin native activity of lytic phages specific to $A$. baumanii evaluated in this study revealed a potent antibacterial activity $(>1 \mathrm{log}$ ) reduction of bacterial density in just one hour of endolysin treatment; this provided promising results to tackle Gram negative bacteria by using low molecular weight endolysins which are of high level of native antibacterial activity.

\section{Acknowledgments}

Regard and gratefulness should be presented to the staff members Department of Microbiology at the College of Medicine, AlNahrain University for their assistance.

\section{Authors contribution}

Dr. Abdel-Ameer: designed the research and conducted study analysis. Jasim: conducted the research.

\section{Conflict of interest}

There is no conflict of interest among authors of this manuscript. 


\section{Funding}

There is no funding source for this research.

\section{References}

1. Cantas L, Shah QA, Cavaco LM, et al. A brief multidisciplinary review on antimicrobial resistance in medicine and its linkage to the global environmental microbiota. Front Microbiol. 2013; 4: 96 . doi: 10.3389/fmicb.2013.00096.

2. Hofer $U$. The cost of antimicrobial resistance. Nature Rev Microbiol. 2019. 17(3): 78-89. doi: https://doi.org/10.1038/s41579-018-0125-x.

3. Murray CK, Yun HC, Griffith ME, et al. Recovery of multidrug-resistant bacteria from combat personnel evacuated from Iraq and Afghanistan at a single military treatment facility. Mil Med. 2009; 174(6): 598-604. doi: https://doi.org/10.7205/MILMED-D-038008.

4. Calhoun DA, Jones D, Textor $S$, et al. Resistant hypertension: diagnosis, evaluation, and treatment: a scientific statement from the American Heart Association Professional Education Committee of the Council for High Blood Pressure Research. Circulation. 2008; 117(25): e510-26. doi: 10.1161/CIRCULATIONAHA.108.189141.

5. O'Neill, J. Tackling drug-resistant infections globally: final report and recommendations. The review on antimicrobial resistance. 2016. Available at: https://amr-

review.org/sites/default/files/160518_Final\%20pape r_with\%20cover.pdf.

6. Abedon ST, Kuhl SJ, Blasdel BG, et al. Phage treatment of human infections. Bacteriophage. 2011; 1(2): 66-85. doi: 10.4161/bact.1.2.15845.

7. Hendrix RW, Smith MC, Burns RN, et al. Evolutionary relationships among diverse bacteriophages and prophages: all the world's a phage. Proc. Natl. Acad. Sci. U.S.A. 1999; 96: 2192-7. doi: 10.1073/pnas.96.5.2192.

8. Clokie MRJ, Millard AD, Letarov AV, et al. Phages in nature. Bacteriophage. 2011; 1(1): 31-45. doi:10.4161/bact.1.1.14942.

9. Flores CO, Meyer JR, Valverde S, et al. Statistical structure of host-phage interactions. Proc. Natl. Acad. Sci. U.S.A. 2011; 108(28): E288E297.doi:10.1073/pnas.1101595108.

10. Ormälä AM, Jalasvuori M.. Phage therapy: should bacterial resistance to phages be a concern, even in the long run? Bacteriophage. 2013; 3(1): e24219. doi: 10.4161/bact.24219.

11. Falagas ME, Vardakas $K Z$, Kapaskelis $A$, et al. Tetracyclines for multidrug-resistant Acinetobacter baumannii infections. Int J Antimicrob Agents. 2015; 45(5): 455-60. doi: 10.1016/j.ijantimicag.2014.12.031.

12. Merril CR, Scholl D, Adhya SL. The prospect for bacteriophage therapy in Western medicine. Nat Rev Drug Discov. 2003; 2(6): 489-97. doi: 10.1038/nrd1111.
13. Vandepitte J, Engbaek K, Rohner p, et al. Basic laboratory procedures in clinical bacteriology. 2nd ed. Geneva, World Health Organization. 2003. p. 10321. http://www.who.int/iris/handle/10665/42696.

14. Clinical and Laboratory Standards Institute. M100S24 Performance standards for antimicrobial susceptibility testing: Twenty-fourth informational supplement. USA: Clinical and Laboratory Standards Institute (CLSI). 2014.

15. Knezevic $P$, Petrovic $O$. A colorimetric microtiter plate method for assessment of phage effect on Pseudomonas aeruginosa biofilm. J Microbiol Methods. 2008; 74(2-3): 114-8. doi: 10.1016/j.mimet.2008.03.005.

16. Jassim SA, Abdualamir AS, Abu baker F. Methods for bacteriophage design. In: International application published under the patent cooperation (PCT)" (W.I.P. organization, ed.), 2010. Vol.WO2010064044 A1.

17. Simmons M, Donovan DM, Siragusa GR, et al. Recombinant expression of two bacteriophage proteins that lyse clostridium perfringens and share identical sequences in the C-terminal cell wall binding domain of the molecules but are dissimilar in their Nterminal active domains. J Agric Food Chem. 2010 Oct 13;58(19):10330-7. doi: 10.1021/jf101387v.

18. ALHuraishi MAM. Molecular detection of multidrug resistance Acinetobacter baumannii from different clinical samples. MSc thesis. Al-Nahrain University; 2017.

19. Mashhadani EIJA. Study the activity of Bacteriocin produced from Lactobacillus plantorum on virulence factors of Acinetobacter baumannii. MSc. thesis AlMustasiriyah University; 2010.

20. Al-Marjani MF, Al-Ammar MHM, kadhim EQ. Occurrence of ESBL and MBL genes in Pseudomonas aeruginosa and Acinetobacter baumannii isolated from Baghdad, Iraq. Int J Curr Res. 2013; 5(9): 2482-6.

21. Qureshi ZA, Hittle LE, O'Hara JA, et al. ColistinResistant Acinetobacter baumannii: Beyond Carbapenem Resistance. Clin Infect Dis. 2015; 60(9): 1295-303. doi: 10.1093/cid/civ048.

22. Al-Saleem NH. Genotyping relatedness of Acinetobacter baumannii isolated from medical City/Baghdad. PhD thesis. College of Science. University of Baghdad; 2013.

23. Pelletier MR, Casella LG, Jones JW, et al. Unique structural modifications are present in the lipopolysaccharide from colistin-resistant strains of Acinetobacter baumannii. Antimicrob Agents Chemother. 2013; 57(10): 4831-40. doi: 10.1128/AAC.00865-13.

24. Arroyo LA, Herrera CM, Fernandez L, et al. The pmrCAB operon mediates polymyxin resistance in Acinetobacter baumannii ATCC 17978 and clinical isolates through phosphoethanolamine modification of lipid A. Antimicrob Agents Chemother. 2011; 55(8): 3743-51. doi: 10.1128/AAC.00256-11.

25. Jain R, Danziger LH. Multidrug-resistant Acinetobacter infections: an emerging challenge to 
clinicians. Ann Pharmacother. 2004; 38(9): 1449-59. doi: 10.1345/aph.1D592.

26. Rodriguez-Martinez JM, Nordmann P, Ronco E, et al. Extended-spectrum cephalosporinase in Acinetobacter baumannii. Antimicrob Agents Chemother. 2010; 54(8): 3484-8. doi: 10.1128/AAC.00050-10.

27. Bragg $R$, van der Westhuizen $W$, Lee $J Y$, et al. Bacteriophages as potential treatment option for antibiotic resistant bacteria. Adv Exp Med Biol. 2014; 807: 97-110. doi: 10.1007/978-81-322-1777-0_7.

28. Kusradze I, Karumidze N, Rigvava $S$, et al. Characterization and Testing the Efficiency of Acinetobacter baumannii Phage vB-GEC_Ab-M-G7 as an Antibacterial Agent. Front Microbiol. 2016; 7: 1590. doi: 10.3389/fmicb.2016.01590.

29. Regeimbal JM, Jacobs AC, Corey BW, et al. Personalized therapeutic cocktail of wild environmental phages rescues mice from Acinetobacter baumannii wound infections. Antimicrob Agents Chemother. 2016; 60(10): 580616. doi: 10.1128/AAC.02877-15.

30. Merabishvili M, Vandenheuvel D, Kropinski AM, et al. Characterization of newly isolated lytic bacteriophages active against Acinetobacter baumannii. PLoS One. 2014; 9(8): e104853. doi: 10.1371/journal.pone.0104853.

31. Lobocka M, Hejnowicz MS, Gagała $U$, et al. The first step to bacteriophage therapy-how to choose the correct phage. In: Borysowski J, Miedzybrodzki R, Górski A. (eds). Phage therapy: current research and applications. Norfolk: Caister Academic Press; 2014.

32. Jassim SA, Abdulamir AS, Abu Bakar F. Phage-based limulus amoebocyte lysate assay for rapid detection of bacteria. 2011. https://patentimages.storage.googleapis.com/4f/a1/ be/5c71cee97cac20/W02011098820A1.pdf.

33. Chan BK, Abedon ST, Loc-Carrillo C. Phage cocktails and the future of phage therapy. Future Microbiol. 2013; 8(6): 769-83. doi: 10.2217/fmb.13.47.

34. Kelly D, McAuliffe O, Ross RP, et al. Development of a broad-host-range phage cocktail for biocontrol. Bioeng Bugs. 2011; 2(1):31-7. doi: 10.4161/bbug.2.1.13657.

35. Chan BK, Abedon ST. Phage therapy pharmacology: phage cocktails. Adv Appl Microbiol. 2012; 78: 1-23. doi: 10.1016/B978-0-12-394805-2.00001-4.

36. Peleg AY, Seifert H, Paterson DL. Acinetobacter baumannii: emergence of a successful pathogen. Clin Microbiol Rev. 2008; 21(3): 538-82. doi: 10.1128/CMR.00058-07.

37. Lai MJ, Lin NT, Hu A, et al. Antibacterial activity of Acinetobacter baumannii phage $\varphi A B 2$ endolysin (LysAB2) against both gram-positive and gramnegative bacteria. Appl Microbiol Biotechnol. 2011; 90(2): 529-39. doi: 10.1007/s00253-011-3104-y.
38. Briers Y, Volckaert G, Cornelissen A, et al. Muralytic activity and modular structure of the endolysins of Pseudomonas aeruginosa bacteriophages phiKZ and EL. Mol Microbiol. 2007; 65(5): 1334-44. doi: 10.1111/j.1365-2958.2007.05870.x.

39. Miroshnikov KA, Faizullina NM, Sykilinda NN, et al. Properties of the endolytic transglycosylase encoded by gene 144 of Pseudomonas aeruginosa bacteriophage phiKZ. Biochemistry (Mosc). 2006; 71(3): 300-5.

40. Paradis-Bleau C, Cloutier I, Lemieux L, et al. Peptidoglycan lytic activity of the Pseudomonas aeruginosa phage phiKZ gp144 lytic transglycosylase. FEMS Microbiol Lett. 2007; 266(2): 201-9. DOI: 10.1111/j.1574-6968.2006.00523.x.

41. Junn HJ, Youn J, Suh KH, et al. Cloning an expression of Klebsiella phage K11 lysozyme gene. Protein Expr. Purif. 2005; 42(1): 78-84. doi: 10.1016/j.pep.2005.03.026.

42. Mikoulinskaia GV, Odinokova IV, Zimin AA, et al. Identification and characterization of the metal iondependent L-alanoyl-Dglutamate peptidase encoded by bacteriophage T5. FEBS J. 2009; 276(24): 7329-42. doi: 10.1111/j.1742-4658.2009.07443.x.

43. Schmelcher $M$, Shabarova $T$, Eugster MR, et al. Rapid multiplex detection and differentiation of Listeria cells by use of fluorescent phage endolysin cell wall binding domains. Appl Environ Microbiol. 2010; 76(17): 5745-56. doi: 10.1128/AEM.00801-10.

44. Loessner MJ, Kramer K, Ebel F, et al. C-terminal domains of Listeria monocytogenes bacteriophage murein hydrolases determine specific recognition and high-affinity binding to bacterial cell wall carbohydrates. Mol. Microbiol. 2002; 44(2): 335-49.

45. Lood R, Winer BY, Pelzek AJ, et al. Novel phage lysin capable of killing the multidrug-resistant gramnegative bacterium Acinetobacter baumannii in a mouse bacteremia model. Antimicrob Agents Chemother. 2015; 59(4): 1983-91. doi: 10.1128/AAC.04641-14.

46. Saleem F, Ahmad S, Yaqoob Z, et al. Comparative study of two bacteriocins produced by representative indigenous soil bacteria. Pak J Pharm Sci. 2009; 22(3): 252-8.

47. Hibbing ME, Fuqua $C$, Parsek MR, et al. Bacterial competition: surviving and thriving in the microbial jungle. Nat Rev Microbiol. 2010; 8(1): 15-25. doi: $10.1038 /$ nrmicro2259.
Correspondence to Hayder N. Jasim
E-mail: haider.nasef@gmail.com
Received Oct. 25 2017
Accepted Jan. $8^{\text {th }} 2018$ 